This is a non-peer-reviewed manuscript submitted to EarthArxiv. The manuscript was submitted for review to WIREs Water.

\title{
On doing large-scale hydrology with Lions: Realizing the value of perceptual models and knowledge accumulation
}

\author{
Thorsten Wagener ${ }^{1,2,{ }^{*}}$, Tom Gleeson ${ }^{3,4}$, Gemma Coxon ${ }^{5,2}$, Andreas Hartmann ${ }^{1,6}$, Nicholas \\ Howden $^{1,2}$, Francesca Pianosi ${ }^{1,2}$, Mostaquimur Rahman ${ }^{1,2}$, Rafael Rosolem ${ }^{1,2}$, Lina Stein ${ }^{1}$, \\ Ross Woods ${ }^{1,2}$ \\ ${ }^{1}$ Department of Civil Engineering, University of Bristol, Bristol, UK \\ ${ }^{2}$ Cabot Institute for the Environment, University of Bristol, Bristol, UK \\ ${ }^{3}$ Department of Civil Engineering, University of Victoria, Victoria, British Columbia, Canada \\ ${ }^{4}$ School of Earth and Ocean Sciences, University of Victoria, Victoria, British Columbia, \\ Canada \\ ${ }^{5}$ School of Geographical Sciences, University of Bristol, Bristol, UK \\ ${ }^{6}$ Institute of Earth and Environmental Sciences, University of Freiburg, Freiburg, Germany \\ *Corresponding author: thorsten.wagener@bristol.ac.uk
}

\begin{abstract}
Moving the study domain in hydrology to larger and larger regions leaves us with significant knowledge gaps because we are unable to observe the hydrology of many parts of the world, while in-depth hydrologic studies cover only a fraction of our landscape. On medieval maps, knowledge gaps were shown as images of lions. How do we best acknowledge and reduce these gaps in hydrology, i.e. our hydrologic lions? The accumulation of knowledge has been postulated as the fundamental mark of scientific advancement by some philosophers of science. In hydrology, knowledge accumulation has been somewhat fragmented, left as a pursuit for (often brilliant) individuals rather than emphasised as a necessary focus for the research community. Our knowledge of a region's hydrology originates from available observations. However, the ability of observations to reliably characterise hydrological phenomena is limited, and large areas of the globe lack detailed observations. In this commentary we propose two strategies to rectify these deficiencies. First, the use of shared perceptual models as ways to capture, debate and test our experience with different hydrologic systems. Second, improved knowledge accumulation in hydrology by more strongly focusing on knowledge extraction from available peer-reviewed articles. This effort should include the addition of meta-data to tag hydrologic journal articles and by developing a related hydrological database that would enable searching, organizing and analysing previous studies in a hydrologically meaningful manner.
\end{abstract}

\section{Keywords}

Large Scale Hydrology, Uncertainty, Knowledge Accumulation, Perceptual Model, Metadata, Machine Learning

\section{INTRODUCTION}


Humanity has always been uncomfortable with knowledge gaps. When the explorer John Cabot left Bristol harbour in 1497 to chart a new route to Asia, he was trying to fill one such knowledge gap (and filled a different one - the existence of North America - by accident). Such attempts to meet key knowledge gaps had not been common at the time, a circumstance nicely visualized in the example of two maps. In his macro-history of humanity, Yuval Noah Harari (2015) discusses two world maps that, whilst being drawn within less than 100 years of each other, were separated by key events including the voyages of John Cabot and Christopher Columbus (Fig. 1). The Fra Mauro world map from 1459 shows the world in great detail with hundreds of illustrations and thousands of descriptive texts (Fig. 1a), which is surprising given the poor state of knowledge about the world at the time. Looking more closely, however, one finds that this and other maps from the period included imagined representations in unexplored (unknown) areas. Indeed, it was customary practice at the time to show monsters rather than to leave spaces empty suggesting that it is undesirable and dangerous to explore such places. Ancient Roman and Medieval mapmakers demarcated such unknown areas with the phrase HIC SUNT LEONES, "here are lions" (or alternatively with HIC SUNT DRACONES, "here are dragons") - thus populating unknown areas with creatures that would instil fear in the reader (Agostinho et al., 2019). Fewer than 100 years later the Salviati Planisphere map from 1525 (Fig. 1b) shows the newly found eastern coasts of North and South America, but also reveals empty space in thus far unexplored areas. The $16^{\text {th }}$ century map reveals where knowledge gaps exist by daring to leave such areas white, thus inviting explorations to discover what is beyond the edge of current knowledge. Rather than fearing ignorance, this step of acknowledging the unknown became a scientific goal in itself - an important scientific belief in modernity.

So, what is the link between these lions and hydrology? In large-scale hydrology, we rely on datasets to describe physical properties and hydro-meteorological fluxes from local to global scales, while model outputs produce maps and time-series of hydrologic variables to simulate their variability across large regions - like countries or even globally. In this endeavour we unavoidably move our hydrologic investigation away from highly studied headwater catchments, hillslopes, aquifers or Fluxnet sites to large regions of poorly explored and poorly characterised landscapes (Fan et al., 2019). Relevant hydrologic quantities and properties as well as their uncertainties tend to be poorly determined by scarce historical observations away from areas where observations are focused (Beven et al., 2018). So, how can we deal with such knowledge gaps or epistemic uncertainties apart from hoping for potential new future measurement techniques? Large scale outputs of hydrologic models or compiled datasets will include hydrologic lions rather than meaningful information in some places. We need strategies to distinguish these areas so that areas can be highlighted as white, i.e. in need of further exploration. This is of course mostly not a question of information versus no information (white space), but rather a question of how much can we know, what is the basis for this knowledge, and how confident are we in our knowledge?

In hydrology we have seen our knowledge and analysis domain expand from the catchment to continental and even global scales, increasingly with the help of global hydrologic models. Global hydrologic models have emerged not just as the endeavours of particularly brave scientists (e.g. Manabe and Holloway Jr, 1975), but rather as tools for regular scientific analysis and increasingly as possible tools for water resource management (Bierkens et al., 2015; Archfield et al., 2015; Straatsma et al., 2016). Hydrology is indeed moving towards 
realizing the "models of everywhere" idea of Beven (2001) at hyper-resolution (Wood et al., 2011). Global and continental-scale hydrologic models increasingly reveal human influence on global fluxes of terrestrial sediments to the oceans (Syvitski et al., 2005), risks to global river biodiversity (Vörösmarty et al., 2010), global depletion of groundwater resources (Wada et al., 2010), impacts of groundwater pumping on our rivers (De Graaf et al., 2019), global drivers of flood risk (Winsemius et al., 2016), impacts of human activity on the global water cycle (Bosmans et al., 2017), and potential implications of climate change for the global freshwater system (Döll et al., 2018).

Equally, we see the emergence of global datasets which add new dimensions to our ability to analyse global hydrology (Lindersson et al., 2020). New global datasets of physical system properties, such as subsurface hydrogeological properties, have been accumulated in recent years (Gleeson et al., 2011; Huscroft et al., 2018). Various global precipitation datasets can be used to force hydrologic models (Beck et al., 2019), while land surface fluxes have been regionalized from flux tower networks to the global scale (Jung et al., 2011). Satellite data provide continuous time estimates of freshwater storage (Rodell et al., 2018; Famiglietti et al., 2015) and the topographic characteristics of our land surface in a hydrologically meaningful manner (Linke et al., 2019; Nardi et al., 2019; Yan et al., 2019), while remotely sensed observations of vertical fluxes are used to create land surface water balances everywhere (Miralles et al., 2011). Increasingly, new global datasets of land cover change and other human interventions in the water cycle are becoming available, such as artificial storage through reservoirs (Lehner et al., 2011; Mulligan et al., 2020). Widely used historical data such as river flows of the Global Runoff Data Centre - GRDC (Grabs et al., 1996) are complemented with other hydrologic response data compilations like karst spring hydrographs (Olarinoye et al., 2020). Most of these datasets are based on direct observations subsequently processed through models for interpretation, interpolation or even extrapolation (Gupta and Nearing, 2014).

The power of such large-scale datasets is maybe best exemplified by the tremendous success of machine learning and other data-based approaches, which often outperform models based on our mechanistic understanding of how nature works (Reichstein et al., 2019; Shen et al., 2018). For example, Boers et al. (2019) find teleconnections patterns in global extreme rainfall by analysing high-resolution satellite data with the help of complex networks. Stolbova et al. (2016) managed to empirically predict the onset of the monsoon two weeks further in advance than previous methods (including predictions from dynamic models). Addor et al. (2018) used random forests to demonstrate the predictability of hydrologic signatures across the US and showed that signatures predictable from descriptors which vary smoothly in space, such as those related to climate, regionalize particularly well. Machine learning tools have also been used widely to turn in-situ observations into global datasets. Jung et al. (2011) use a machine learning strategy - model tree ensembles - to upscale Fluxnet observations of carbon dioxide, water, and energy fluxes to the global scale.

While the combination of global models (both data-based and mechanistic) and global datasets undoubtedly offers tremendous opportunities for scientific advancement and for new scales of management, it also contains hydrologic lions, i.e. knowledge gaps that are currently difficult to address. Current observations of hydrologic fluxes and storages do not allow us to characterize the water balance (especially sub-surface properties) at the abovementioned hyper-resolution (Beven and Cloke, 2012; Beven et al., 2015). Global geological 
data show artefacts such as variability along administrative boundaries due to differences in processing underlying observations across administrative units (Gleeson et al., 2011).

Pedotransfer functions based on soil texture classes, the basis for estimating soil hydraulic properties used in many hydrologic and other models, have been derived from very limited and biased empirical data, while ignoring structural soil characteristics (Or, 2019; Fatichi et al., 2020). Consequently, it is not too surprising that Gutmann and Small (2007) find soil texture only explains a small fraction ( $5 \%$ in their case) of the expected variability of soil hydraulic properties. Similarly, Rosero et al. (2010) found that soil and vegetation parameters, derived as parameter sets through conditioning of the NOAH land surface model to observations from flux towers along a climatic gradient with varying soil and vegetation properties, correlated with the climatic gradient, but not with soil or vegetation properties. These studies place the focus on the transfer functions used to translate underlying observations into hydrologically meaningful data, but are these data postprocessing models sufficiently realistic?

So how do we identify hydrologic lions, and, more importantly, how might we overcome them given that they originate from a lack of observations or even observational capability? In this brief commentary, we discuss two strategies to address this question.

- A focus on perceptual models to pool and test our knowledge

- Improved knowledge accumulation in hydrology

Below we discuss each of these strategies and what role they play.

\section{PERCEPTUAL MODELS TO POOL AND TEST OUR KNOWLEDGE AND EXPERIENCE}

Large scale hydrologic models depend on appropriate datasets to define their parameters (and potentially model structure), and workflows to integrate models and data have become increasingly sophisticated and efficient (Turuncoglu et al., 2013; Leonhard and Duffy, 2014; Leonhard et al., 2016; Blair et al., 2019). Leonhard and Duffy (2013) provide an example of such a workflow that combines web services and data-model workflows to integrate what they refer to as Essential Terrestrial Variables (ETV) into distributed watershed models. Leonhard and Duffy (2013) propose ETV data as the Essential Terrestrial Data necessary to construct watershed models anywhere in the continental USA. These ETV are made up of 100s of terabytes of US datasets organized at the United States Geological Survey (USGS) Hydrological Unit Code (HUC) level-12 scale. Workflows like these facilitate the integration of models and data, where data are at the core of the modelling effort (see Fig. 2a). A priori models built in this manner are the basis for much of our global hydrology (Yang et al., 2019).

Relying heavily on the assimilation of available datasets creates problems when and where currently available datasets are poor descriptors of the underlying hydrologic processes, and it ignores knowledge (or experience) that has been gained but is not easily embedded in datasets. Hartmann et al. (2017) compared groundwater recharge estimates of two large scale models, PCR-GLOBWB and VarKarst-R across the carbonate rock regions of Europe, Northern Africa, and the Middle East. The former is a global integrated hydrologic model based on global datasets, while the latter is a parsimonious and thus simpler model tailored to regions with strong focused recharge processes. The authors found that recharge estimates of the simpler model were more consistent with available observations and local model results. One reason for this result is the underlying perceptual model for VarKarst- $R$ is based on the expected dominant system characteristics of carbonate rock regions, derived 
from experience derived other in highly studied locations. The perceptual model of PCRGLOBWB (at the time) assumed that the world consisted only of two systems: mountains and alluvial plains - the remaining tailoring was done through adjustment of its parameters (Prof Mark Bierkens, Personal Communication). The simpler model used in-depth knowledge from local studies to develop different perceptual models for the main regions, which were then further constrained using similarity principles. Since this early perceptual model was not previously published, it is hard to evaluate the impact it had on the robustness and realism of PCR-GLOBWB results and interpretations. We suggest that giving a more central role to tailored perceptual models - for example by making them open and shared - would provide a helpful way forward (Fig. 2b), whilst opening up questions of how such models should be presented, discussed and evolved.

We propose that a currently underutilized way to collect and share information (defined as data seen in a particular context) as well as knowledge (defined here as our understanding gained through experience) valuable for large scale modelling lies in openly shared perceptual models. Perceptual models in hydrology are seen as the evolving understanding of real-world system based on the interpretation of all available information, influenced by the hydrologist's unique experience and training (Beven, 2001; Seibert and McDonnell, 2002; Gupta et al., 2008). Sometimes, perceptual models are seen as one step in a modelling chain where they form the basis of more formal system conceptualizations, e.g. in hydrogeology (Brassington and Younger, 2010). Here we use the term perceptual model as the (typically visual) representation of the hydrologist's understanding of the system, including their subjective understanding, speculation and opinion, but without any consideration of subsequent model building efforts (e.g. whether the subsequent computational model is spatially lumped or distributed). As has been discussed in-depth elsewhere, perceptual models are seen as subjective and individual (Beven, 2001). We do not, of course, claim that any modeller would build and apply large-scale hydrologic model without perceptual models as a baseline: the issue is rather one of publishing and sharing them so that differences in the interpretation of available information about the hydrology of a place becomes visible and can be debated and addressed.

While many journal papers, e.g. those describing modelling studies, will include a schematic depiction of the computational model, few include the underlying perceptual model that the modeller had in mind. The schematic of the computational model includes assumptions related to the implementation choices of the modeller, e.g. they might select a spatially lumped or a grid-based model. However, this schematic (especially for relatively simple models) might be quite far removed from the underlying system perception the modeller started with. We have not, so far, systematically collected and used the knowledge provided in perceptual models for global hydrologic modelling. Open perceptual models would provide a forum to discuss and challenge our current thinking about the dominant hydrologic processes of different places. They might also offer us an opportunity to discuss the relative difference between places - which might already significantly improve our understanding of dominant process controls (Rogger et al., 2012).

These perceptual models also directly relate to the wider problem of transferring knowledge that has been gained in a specific catchment to other (even seemingly similar) places. As McDonnell et al. (2007, page 2) conclude: As a community, and as individuals, we have progressed along a philosophical path that "if we characterize enough hillslopes and watersheds around the world through detailed experimentations, some new understanding 
is bound to emerge eventually." How can we complement a focus on understanding individual places with one of understanding regional scale variability? Put another way, how can we construct our hydrologic knowledge landscape so that it transcends the uniqueness of place? Investigating individual catchments in depth unavoidably confronts us with high levels of complexity (Teztlaff et al., 2008) and unique features that distinguish one particular catchment from another (Beven, 2000). However, at some higher level, we continue to assume that principles of hydrologic similarity apply and are helpful for regionalization and classification (McDonnell and Woods, 2004; Wagener et al., 2007). Part of the problem is a lack of hydrologically meaningful descriptors of catchments (or other hydrologic units of relevant size). Climatic and topographic catchment descriptors have been assessed widely (e.g. Seibert and McGlynn, 2007; Knoben et al., 2018), and they have been shown to be valuable predictors of some hydrological responses (e.g. Troy et al., 2008; Kuentz et al., 2017; Addor et al., 2018). Subsurface characteristics on the other hand are much harder to observe and characterize (Beven and Cloke, 2012; Merz et al., 2020), and therefore might have to be equally based on our expectations as they are on directly observable properties. Few attempts to integrate (expected) system conceptualizations and data have been made thus far (Boorman et al., 1995).

Open and structured discussions of perceptual models might reveal divergent expectations of the dominant hydrologic processes in particular places, before we have taken in-situ measurements. A starting point could be the previously proposed simple perceptual models of comparative hydrology (Falkenmark and Chapman, 1989), which would nonetheless require much more tailoring to each location using top-down thinking already applied in many modelling studies (Young, 2003; Sivapalan et al., 2003). How much can we reduce model prediction uncertainty if we do not just constrain the expected hydrological behaviour with available data, but also using our expectations across large scales? Thus, building on previous ideas at the catchment scale as discussed by Seibert and McDonnell, (2002), Savenije (2010) and Kelleher et al. (2017). Some studies have shown that simpler measurements, sensibly distributed in space and time, might provide insight that is more transferable than that produced by much more in-depth measurements in very few places (Jencso and McGlynn, 2012).

Where do our models diverge from the expected hydrologic behaviour derived from our perceptual model(s) (if no suitable observations of the system response for direct assessment are available)? It has been widely discussed that the more complex a model (or a hypothesis), the harder it is to reject it during testing because it has more degrees of freedom (parameters) and thus greater variability in its outputs (Young et al., 1996; Oreskes et al., 1994; Kirchner, 2006). This is an area of research that - surprisingly - has received little attention apart from studies focusing on minimally parameterized (parsimonious) catchment-scale rainfall-runoff models (Perrin et al., 2003). There is, however, no reason why this principle should not apply to all models beyond rainfall-runoff models with 5-6 parameters, even physically based ones. Large-scale hydrologic models have so far largely not been based on such principles of parsimony (Clark et al., 2017), and thus include empirical parameters with unclear physical basis (Cuntz et al., 2016) or parameters whose relevance is difficult to establish during model evaluation (Demaria et al., 2007). Recent attempts to build parsimonious and physically based process representations for large-scale modelling have shown it is feasible to achieve mechanistic process representations without a large number of parameters (Sarrazin et al., 2018; Rahman et al., 2019). Such models thus 
offer higher testability and fewer problems of data support, which would further ease the assessment of competing perceptual models.

\section{IMPROVED KNOWLEDGE ACCUMULATION IN HYDROLOGY}

The traditional philosophy of science considers at least two approaches to scientific advancement. First, the process of scientific evolution proposed by Popper (1959) where hypotheses are falsified through evidence (data) and remain conditionally valid only as long as they are consistent with all available evidence. This idea is comparable with a democratic process where parties are voted in or out depending on their performance. The approach by Popper - one of hypothesis testing - is the strategy widely utilized (or maybe attempted) in hydrology (see for example discussions in Pfister and Kirchner, 2017; Beven, 2018). An alternative view is that science progress is a more unpredictable process based on scientific revolutions as introduced by Kuhn (1962). He assumes that old paradigms are replaced by new ones in a process more comparable to overthrowing the government through revolution.

A third idea, less frequently discussed, is that knowledge accumulation itself constitutes scientific advancement in its own right - rather than just being a component in democratic or revolutionary style scientific processes mentioned above. Does science already advance if we accumulate knowledge? Or only if this knowledge leads to the development of new ideas or theories? Bird (2007) suggests that: Science (or some particular scientific field or theory) makes progress precisely when it shows the accumulation of scientific knowledge; an episode in science is progressive when at the end of the episode there is more knowledge than at the beginning. While Bird was not the first to suggest this concept for scientific progress, which can be traced back to Francis Bacon, he nonetheless reenergised the discussion (Mizrahi, 2013). Here, we do not want to answer the question whether knowledge accumulation is equal to scientific progress or not, but rather stress that effective knowledge accumulation is a fundamental element for scientific progress.

We argued in section two that perceptual models are one way towards reducing knowledge gaps (lions) in large scale hydrology. So how and where does knowledge - in support of our perceptual models - accumulate in the field of hydrology? And especially, how well does it accumulate? Given that we regularly ask what questions remain in hydrology (Sivapalan, 2009; Blöschl et al., 2019), it seems equally relevant to ask what we already know and how confident we are that all available knowledge has been captured. An exhaustive case study of how the hydrologic community has accumulated knowledge in a particular area was the synthesis effort within the Predictions in Ungauged Basins (PUB) initiative (Blöschl et al., 2013; Hrachowitz et al., 2013). Over 100 authors produced a compendium of what had been learned about the PUB problem - often rerunning analyses to make them consistent and comparable. While this work is a good example of what can be achieved through such an effort, it used more resources than those normally available. Different - more sustainable and routine - strategies to achieve such a synthesis are needed to address a number of questions in hydrology (Blöschl et al., 2019).

Knowledge is shared in a variety of ways through peer-reviewed journal papers (mainly), but also through textbooks, field trips and supervisors, each of which have limitations. However, while this meant reading a few hundred papers per year in the 1970s, it now requires assessing in excess of 2,500 papers per year (almost 7 per day), even if we only focus on the main hydrology journals (Fig. 3). Many, if not most, of these papers will describe what has 
been learned by studying the hydrology of a particular place, or a sample of places, thus providing insight into the hydrologic variability found in our highly heterogeneous world (Beven, 2000), with existing meta-analyses showing the great potential for learning by reviewing and synthesising existing literature (e.g. Price, 2011). Review papers play an important role as well, regardless of whether they are published in our main journals or in journals which specialize on reviews. In either case, the problem is that reviews often do not consider a large fraction of the papers in an area, but more likely propose a new organization of available knowledge with a limited number of papers as examples, i.e. they are more qualitative reviews (which of course does not mean that they are not useful!). In response to this issue, some journals (e.g. Environmental Research Letters) specifically advocate more quantitative, meta-data driven reviews. These quantitative, meta-data driven reviews are a useful compliment to more qualitative reviews, and require an easier way to identify and organize existing literature for synthesis.

We might also look at textbooks, field trips or graduate supervision for this knowledge. In contrast to journal papers, most hydrology textbooks provide the underlying hydrologic theory, but the tailoring to a specific place is difficult to encapsulate in general guidelines (Wagener et al., 2011). Field trips are a tangible and impactful way of sharing knowledge, and new ways for sharing our experience with understanding the hydrology of specific catchments or regions are emerging. For example, Google Earth Engine and other virtual earth educational tools provide exciting opportunities for "virtual field visits" in combination with those field trips that can be done locally. Prof Tom Dunne pointed out (Personal Communication) that most students will be offered accumulated knowledge through their supervisors' experience. However, each supervisor shares very different knowledge and can only reach a small number of students so it seems dissatisfying as a baseline for our scientific community. It is important to have exceptional researchers who provide inspiration and creativity, but it would be beneficial to have a better general baseline for our accumulated knowledge.

So, we need a better way to find, extract and accumulate the hydrological knowledge hidden in over 2500 papers published per year. Hradec et al. (2019) call this the challenge of assessing information "trapped in the text". The sheer volume of text means that, unassisted, we cannot hope to read all available sources, nor even to keep up to date with all advances in a particular field (Hradec et al., 2019). For example: How many studies last year analysed the water balance of catchments located in the sub-tropics? Or, have the Nash Sutcliffe Efficiency values of models applied to semi-arid catchments improved over the last decade? We can currently only answer these questions by looking through large numbers of papers in a tedious manner. In other fields, it has been recently proposed to approach this problem through machine learning, which has been shown to be able to extract scientific knowledge hidden in scientific papers (Hradec et al., 2019; Tshitoyan et al., 2019). Tshitoyan et al. (2019) demonstrate what the automated mining of scientific literature can achieve by showing for example that structure-property relationships in materials can be derived from information gathered in this manner. Hradec et al. (2019) developed a software tool to perform a similar automated semantic analysis of a large number of documents to support European policy making. While such approaches are not yet widely explored, hydrology, with its heterogeneous study entities, is exceptionally well placed to test its potential (e.g. see the study by Addor and Melsen, 2019). Using machine learning to find and organize our knowledge seems at least as relevant as its use for making better hydrological predictions. 
Regardless of the advancements made with text mining algorithms, the hydrological community needs to advance how knowledge synthesis is supported. The PUB effort (Blöschl et al., 2013), for example, has shown how tremendously difficult it is to simply identify who has studied a particular catchment in the past, e.g. to ask how well their hydrologic model performed. A starting point would be the inclusion of mandatory metadata for each hydrologic study in each journal article as Essential Hydrological Descriptors in addition to the standard key words or subject tags: geolocation, time period, spatial and temporal resolution, fluxes and stores studied at the hydrologic study area. Such metadata tagging is already done in some data journals such as Scientific Data which includes machine-readable metadata on location, time period etc. for every article. We suggest that this needs to be expanded to all journal articles published in hydrology (unless they are purely theoretical) so that the identification and synthesis of studies, e.g. for a particular location and time period, is highly simplified. We would also need to add such machine-readable metadata tagging retrospectively to the many articles already published, so that we do not lose the information stored there and to continue to utilize what has been learned.

Simply organizing all published hydrologic studies on a particular topic, e.g. flooding or groundwater recharge rates, by geolocation, would enable us to see where time and space clusters of studies exist and which studies we can compare for consistency. More importantly, it would highlight white spaces on the map of global hydrology, showing which catchments or regions have never been studied locally. Clearly the regions of Europe and North America will be densely populated with study locations, but how many places in the developing world have never been studied in the peer-reviewed scientific literature, or have actually been studied and their results published in papers that are unfortunately often rather poorly cited?

Such metadata should describe characteristics that are unlikely to change - such as the location and time period covered by a study. They could form the basis for developing suitable further descriptors to analyse such studies during syntheses. Imagine a Web of Hydrology (rather than a Web of Science) where the papers (identified by the DOI and their metadata) are connected with hydrologically relevant information that would be calculated from one or more common global datasets. Such descriptors could include, for example, climate descriptors to group existing studies not just by location, but by the similarity of the climate they were in (e.g. all studies performed in cold arid regions). The community debate around what climate (or topographic or geologic or ...) descriptors should form the basis for organizing our hydrology would be a very interesting and relevant study by itself (e.g. discussions by Winter, 2001; McDonnell and Woods, 2004; Buttle, 2006; Wagener et al., 2007). Including multiple datasets would enable at least a basic assessment of the uncertainty in how well we can characterize a place and a time period. This database would also slowly grow through efforts that extract and submit the hydrologically relevant information from journal papers such as groundwater recharge estimates or the performance of a hydrologic model applied to a particular catchment.

A key question is of course how we would motivate and incentivize the community to do so. Adding additional metadata to future papers would simply be a requirement by the journal. To add these to historical articles might require a paid activity maybe even done by nonhydrologists like in Mechanical Turk (https://www.mturk.com). A more interesting model for motivation might be to gamify this activity as well as the subsequent analysis. 


\section{CONCLUSIONS}

The outputs of regional to global scale inquiries in hydrology unavoidably contain hydrologic lions, i.e. knowledge gaps. Our observations are too sparse, our datasets are not equally valid everywhere due to the empirical post-processing models they are based on, and we miss key processes due a lack of measurement capability. All of these are simply statements of the present state of our science, and we are not the first to point them out. The wider problem is that few studies highlight such knowledge gaps and their consequences where they exist. We drew a comparison with cartography in the $15^{\text {th }} / 16^{\text {th }}$ century where cartographers shifted from filling all parts of the map with being content to leaving large areas white. White spaces represented significant knowledge gaps that invited exploration. Highlighting knowledge gaps became a key outcome, rather than something to hide. How many large-scale maps of hydrologic model predictions or hydrologic data have been published with white areas highlighting knowledge gaps? Furthermore, while this would be a good start, how do we reduce these knowledge gaps in hydrology?

First, open and shared collective perceptual models. Hydrology as a science is strongly dependent on experience. This experience is difficult to share and pass on. One strategy to improve this sharing, we believe, lies in the development of collective and open perceptual models that evolve if new insight becomes available. Such perceptual models would have to be developed with a granularity that is sufficient to derive testable hypotheses, but not too fine, because this would distract the focus from dominant processes which should be captured. Simple perceptual models that capture our expectation of how a system will behave already exist - e.g. within the comparative hydrology framework by Falkenmark and Chapman (1989). More complex and spatially distributed versions transferred to larger scales are required to facilitate where our understanding converges or diverges when applied outside of experimental catchments. Even weak constraints on hydrologic dynamics derived from such perceptual models might help to constrain acceptable model behaviour as has been shown at the catchment scale (Seibert and McDonnell, 2002).

Second, improved knowledge accumulation. We argue that knowledge accumulation is poor in the field of hydrology and needs to become a stronger focus. While the sharing of insights through collectively developed and shared perceptual models would be a first step, much of our knowledge is captured in journal articles. Here, semantic data mining algorithms might offer the chance to harvest existing knowledge in an effective manner. In the future, we need to improve the efficiency of extracting and synthesising knowledge from future published work. To do so would require a meta-data tagging of journal papers with Essential Hydrological Descriptors such as geolocation and time period studied. A separate open database could become a community virtual laboratory by linking these essential meta-data to evolving descriptors of climatic, topographic, or other properties.

Some 350 years after John Cabot had set sail to the West from Bristol harbour, Alexander von Humboldt published a, for the time, incredibly comprehensive portrait of nature in the first volume of his work Cosmos: A Sketch of a Physical Description of the Universe in 1845. Humboldt's Cosmos was largely the results of multiple long expeditions in the Americas to explore some of the white areas shown in the Salviati Planisphere (Fig. 1b). His aim was "... to grasp Nature's essence under the cover of outer appearances" by studying the "perceptible world", an objective akin to Dooge's search for hydrologic laws (Dooge, 1986). Humboldt took an incredible 25 years to write his five-volume Cosmos while corresponding by letter with scientists across the globe on topics including botany, geology, geography and 
volcanology. We have since moved on to communicate via (increasingly open) journal articles, and via exchanges at conferences and online meetings. We believe we need to urgently rethink how we share, debate and ultimately accumulate hydrologic knowledge given the opportunities provided by web-based tools and machine learning - this might help us to tame some of our lions.

\section{ACKNOWLEDGEMENTS}

Thanks to Sina Leipold from the University of Freiburg for helpful comments on the philosophy of science. Partial support to TW was provided by a Royal Society Wolfson Research Merit Award [WM170042]. Partial support for TG was provided by a Benjamin Meaker Distinguished Visiting Professorship at the University of Bristol. AH was supported by the Emmy-Noether-Programme of the German Research Foundation (HA 8113/1-1). RR was partially supported by the International Atomic Energy Agency of the United Nations (IAEA/UN) coordinated research project (CRP D12014). FP was supported by the UK Engineering and Physical Sciences Research Council (EPSRC) through a "Living with Environmental Uncertainty" fellowship [EP/R007330/1]. LS was funded as part of the WISE CDT under a grant from the Engineering and Physical Sciences Research Council (EPSRC) [EP/L016214/1].

\section{REFERENCES}

Addor, N. \& Melsen, L.A. (2019). Legacy, rather than adequacy, drives the selection of hydrological models. Water Resources Research, DOI:10.1029/2018WR022958

Addor, N., G. Nearing, C. Prieto, A. J. Newman, N. Le Vine, \& M. P. Clark (2018). A ranking of hydrological signatures based on their predictability in space. Water Resources Research, 54.11, 8792-8812, DOI: 10.1029/2018WR022606

Agostinho, D., D'Ignazio, C., Ring, A., Thylstrup, N.B. \& Veel, K. (2019). Uncertain Archives: Approaching the Unknowns, Errors, and Vulnerabilities of Big Data through Cultural Theories of the Archive. Surveillance \& Society, 17(3/4), 422-441.

Amershi, S., Cakmak, M., Knox, W.B. \& Kulesza, T. (2014). Power to the People: The Role of Humans in Interactive Machine Learning. A.I. Magazine, (35):4, 105-120.

Archfield, S. A., et al. (2015). Accelerating advances in continental domain hydrologic modelling. Water Resources Research, 51, 10078-10091, doi:10.1002/2015WR017498.

Beck, H.E., et al. (2019). MSWEP V2 global 3-hourly 0.1 precipitation: methodology and quantitative assessment. Bulletin of the American Meteorological Society, 100 (3), 473-500

Beven, K. (2000). Uniqueness of place and process representations in hydrological modelling. Hydrology and Earth Systems Sciences, 4, doi.org/10.5194/hess-4-203-2000

Beven, K. (2001). Rainfall-runoff modelling: The primer. Wiley.

Beven, K. (2018). On hypothesis testing in hydrology: Why falsification of models is still a really good idea. Wires Water, https://doi.org/10.1002/wat2.1278. 
Beven, K., Cloke, H., Pappenberger, F., Lamb, R. \& Hunter, N. (2015). Hyperresolution information and hyperresolution ignorance in modelling the hydrology of the land surface. Science China Earth Sciences, 58(1), 22-35.

Beven K J \& Cloke H L. (2012). Comment on "Hyperresolution global land surface modeling: Meeting a grand challenge for monitoring Earth's terrestrial water" by Wood et al (2011). Water Resources Research, 48: W01801, doi: 10.1029/2011WR010982

Bierkens, Marc F P et al. (2015). Hyper-resolution global hydrological modelling - What is next?: "Everywhere and locally relevant". Hydrological Processes, 29 (2), 310-320.

Bird, A. (2007). What is scientific progress? Noûs, 41, 64-89.

Bird, A. (2008). Scientific progress as accumulation of knowledge: A reply to Rowbottom. Studies In History and Philosophy of Science Part A, 39(2), 279-281.

Blair, G.S., Beven, K., Lamb, R., Bassett, R., Cauwenberghs, K., Hankin, B., Dean, G., Hunter, N., Edwards, L., Nundloll, V., Samreen, F., Simm, W. \& Towe, R. (2019). Models of everywhere revisited: A technological perspective. Environmental Modelling and Software, 122, 104521

Boorman, D.B., Hollis, J.M. \& Lilly, A. (1995). Hydrology of soil types: a hydrologically-based classification of the soils in the United Kingdom. Institute of Hydroloy Report No. 126, Wallingford, UK

Bosmans, J.H.C., van Beek, L.P.H., Sutanudjaja, E.H. \& Bierkens, M.F.P. (2017). Hydrological impacts of global land cover change and human water use. Hydrology and Earth System Sciences, 21, 5603-5626.

Brantley, S. L., McDowell, W. H., Dietrich, W. E., White, T. S., Kumar, P., Anderson, S. P., Chorover, J., Lohse, K. A., Bales, R. C., Richter, D. D., Grant, G., \& Gaillardet, J. (2017). Designing a network of critical zone observatories to explore the living skin of the terrestrial Earth. Earth Surface Dynamics, 5, 841-860. doi: 10.5194/esurf-5-8412017

Brassington, F.C. \& Younger, P.L. (2010). A proposed framework for hydrogeological conceptual modelling. Water and Environment Journal, 24(4), 261-273. doi.org/10.1111/j.1747-6593.2009.00173.x

Brown, J. D. (2004). Knowledge, uncertainty and physical geography: towards the development of methodologies for questioning belief. Trans. Inst. Br. Geogr., 29, 367381.

Buttle, J. (2006). Mapping first-order controls on streamflow from drainage basins: the T-3 template. Hydrological Processes, 20, 3415-3422. DOI: 10.1002/Hyp.6519.

Chen, S.A., Michaelides, K., Grieve, S. \& Singer, M.B. (2019). Aridity is expressed in river topography globally. Nature, 573, 573-577.

Cherkauer, K.A., Bowling, L.C. \& Lettenmaier, D.P. (2003). Variable infiltration capacity cold land process model updates. Global and Planetary Change, 38, 151-159.

Clark, M.P., M.F.P. Bierkens, L. Samaniego, R.A. Woods, R. Uijenhoet, K.E. Bennet, V.R.N. Pauwels, X. Cai, A.W. Wood, \& C.D.E Peters-Lidard, (2017). The evolution of process- 
based hydrologic models: Historical challenges and the collective quest for physical realism. Hydrology and Earth System Sciences, doi:10.5194/hess-2016-693.

Cuntz, M., J. Mai, L. Samaniego, M. Clark, V. Wulfmeyer, O. Branch, S. Attinger, \& S. Thober, (2016). The impact of standard and hard-coded parameters on the hydrologic fluxes in the Noah-MP land surface model. Journal of Geophysical Research:

Atmospheres, doi:10.1002/2016JD025097.

De Graaf, I.E.M., Gleeson, T., van Beek, L.P.H., Sutanudjaja, E.H. \& Bierkens, M.F.P. (2019). Environmental flow limits to global groundwater pumping. Nature 574, $90-$ 94, doi.org/10.1038/s41586-019-1594-4

Demaria, E.M., Nijssen, B. \& Wagener, T. (2007). Monte Carlo sensitivity analysis of land surface parameters using the Variable Infiltration Capacity model. Journal of Geophysical Research: Atmospheres, 112(D11).

Döll, P. et al. (2018). Risks for the global freshwater system at $1.5 \mathrm{C}$ and $2 \mathrm{C}$ global warming. Environmental Research Letters, 13 (4), 044038

Dooge, J.C.I. (1986). Looking for hydrologic laws. Water Resources Research, doi.org/10.1029/WR022i09Sp0046S

Evaristo, J. \& J.J. McDonnell, 2017. A role for meta-analysis in hydrology. Hydrological Processes, 31(20):3588-3591, DOI: 10.1002/hyp.11253.

Falkenmark, M. \& Chapman, T.G. (1989). Comparative hydrology: An ecological approach to land and water resources. UNESCO, ISBN: 92-3-102571-6.

Fan, Y, M Clark, D M Lawrence, S Swenson, L E Band, S L Brantley, P D Brooks, W E Dietrich, A Flores, G Grant, J W Kirchner, D S Mackay, J J McDonnell, P C D Milly, P L Sullivan, C Tague, H Ajami, N Chaney, A Hartmann, P Hazenberg, J McNamara, J Pelletier, J Perket, E Rouholahnejad-Freund, T Wagener, X Zeng, E Beighley, J Buzan, M Huang, B Livneh, B P Mohanty, B Nijssen, M Safeeq, C Shen, W van Verseveld, J Volk, \& D Yamazaki (2019). Hillslope Hydrology in Global Change Research and Earth System Modeling. Water Resources Research, DOI: 10.1029/2018WR023903.

Fatichi, S., Or, D., Walko, R., Vereecken, H., Young, M.H., Ghezzehei, T.A., Hengl, T., Kollet, S., Agam, N. \& Avissar, R. (2020). Soil structure is an important omission in Earth System Models. Nature Communications, 11, 522. https://doi.org/10.1038/s41467020-14411-z

Gleeson, T., L. Smith, N. Moosdorf, J. Hartmann, H. H. Dürr, A. H. Manning, L. P. H. van Beek \& A. M. Jellinek (2011). Mapping permeability over the surface of the Earth. Geophysical Research Letters, 38, L02401.doi:10.1029/2010GL045565

Goodwell, A.E., Praveen Kumar, Aaron W. Fellows, \& Gerald N. Flerchinger (2018). Dynamic process connectivity explains ecohydrologic responses to rainfall pulses and drought. Proceedings of the National Academy of Sciences of the United States of America, 115 (37) E8604-E8613.

Grabs, W., T. De Couet, \& J. Pauler (1996). Freshwater fluxes from the continents into the world oceans based on data of the global runoff data base. Tech. Rep. 10, Global Runoff Data Cent., Koblenz, Germany. 
Gutmann, E. D., \& E. E. Small (2007). A comparison of land surface model soil hydraulic properties estimated by inverse modeling and pedotransfer functions. Water Resources Research, 43, W05418, doi:10.1029/2006WR005135.

Harari, Y.N. (2015). Sapiens: A Brief History of Humankind. Harper, 464 pages.

Hartmann, A., Gleeson, T., Wada, Y. \& Wagener, T. (2017). Enhanced groundwater recharge rates and altered recharge sensitivity to climate variability through subsurface heterogeneity. Proceedings of the National Academy of Sciences of the United States of America, 114(11), 2842-2847. https://doi.org/10.1073/pnas.1614941114

Heaven, D. (2019). Why deep-learning Als are so easy to fool. Nature 574, 163-166. doi: 10.1038/d41586-019-03013-5

Hradec, J., Ostlaender, N., Macmillan, C., Acs, S., Listorti, G., Tomas, R., \& Arnes Novau, X. (2019). Semantic Text Analysis Tool: SeTA. EUR 29708 EN, Publications Office of the European Union, Luxembourg, ISBN 978-92-76-01518-5, doi:10.2760/577814, JRC116152

Huscroft, J., T. Gleeson, J. Hartmann, \& J. Börker (2018). Compiling and Mapping Global Permeability of the Unconsolidated and Consolidated Earth: GLobal HYdrogeology MaPS 2.0 (GLHYMPS 2.0). Geophysical Research Letters, doi.org/10.1002/2017GL075860.

Jencso, K.G., \& B.L. McGlynn (2012). Hierarchical controls on runoff generation: Topographically driven hydrologic connectivity, geology, and vegetation. Water Resources Research, 47, W11527, doi:10.1029/2011WR010666

Jung, M., et al. (2011). Global patterns of land-atmosphere fluxes of carbon dioxide, latent heat, and sensible heatderived from eddy covariance, satellite, and meteorological observations. Journal of Geophysical Research,116, G00J07, doi:10.1029/2010JG001566.

Kirchner, J. W. (2006). Getting the right answers for the right reasons: Linking measurements, analyses, and models to advance the science of hydrology. Water Resources Research, 42, W03S04, doi:10.1029/2005WR004362.

Kuentz, A., Arheimer, B., Hundecha, Y., \& Wagener, T. (2017). Understanding hydrologic variability across Europe through catchment classification. Hydrology and Earth System Sciences, 21, 2863-2879, https://doi.org/10.5194/hess-21-2863-2017.

Kuhn, T.S. (1962). The structure of scientific revolutions. University of Chicago Press, USA.

Lehner, B. et al. (2011). High-resolution mapping of the world's reservoirs and dams for sustainable river-flow management. Frontiers in Ecology and the Environment 9 (9), 494-502.

Leonard, L.N., Madduri, K. \& Duffy, C.J. (2016). Tuning Heterogeneous Computing Platforms for Large-Scale Hydrology Data Management. IEEE Transactions on Parallel and Distributed Systems, 27, 9, 2753-2765.

Leonard, L.N. \& Duffy, C.J. (2014). Automating data-model workflows at a level 12 HUC scale: Watershed modeling in a distributed computing environment. Environmental Modelling and Software, 61, 174-190. 
Lindersson, S., Brandimarte, L., Mård, J. \& Di Baldassarre, G. (2020). A review of freely accessible global datasets for the study of floods, droughts and their interactions with human societies. WiresWater, https://doi.org/10.1002/wat2.1424

Linke, S., Lehner, B., Ouellet Dallaire, C. et al. Global hydro-environmental sub-basin and river reach characteristics at high spatial resolution. Sci Data 6, 283 (2019). https://doi.org/10.1038/s41597-019-0300-6

Loritz, R., Hassler, S.K., Jackisch, C., Allroggen, N., Schaik, L. van, Wienhöfer, J. \& Zehe, E. (2017). Picturing and modeling catchments by representative hillslopes. Hydrology and Earth System Sciences, 21, 1225-1249, doi:10.5194/hess-21-1225-2017

Manabe, S. \& Holloway Jr., J.L. (1975). The seasonal variation of the hydrologic cycle as simulated by a global model of the atmosphere. Journal of Geophysical Research, 80(12), 1617-1694.

Marcus, G. \& Davis, E. (2019). Rebooting Al - Building Artificial Intelligence We Can Trust. Pantheon.

Maxwell, R.M. \& Condon, L.E. Connections between groundwater flow and transpiration partitioning. Science, 353:6297, 377-380 doi:10.1126/science.aaf7891, 2016.

McDonnell, J.J., M. Sivapalan, K. Vaché S. Dunn, G. Grant, R. Haggerty, C. Hinz, R. Hooper, J. Kirchner, M. L. Roderick, J. Selker \& M. Weiler, 2007. Moving beyond heterogeneity and process complexity: A new vision for watershed hydrology. Water Resources Research, 43, W07301, DOI: 10.1029/2006WR005467.

Merz, R., Tarasova, L., \& Basso, S. (2020). Parameter's controls of distributed catchment models-How much information is in conventional catchment descriptors? Water Resources Research, 56, e2019WR026008. https:// doi.org/10.1029/2019WR026008

Miralles, DG, RA De Jeu, JH Gash, TR Holmes, AJ Dolman (2011). Magnitude and variability of land evaporation and its components at the global scale. Hydrology and Earth System Sciences, 967-981.

Mizrahi, M. (2013). What is scientific progress? Lessons from scientific practice. Journal for General Philosophy of Science, 44(2), 375-390.

Mulligan, M., van Soesbergen, A. \& Saenz, L. (2020). GOODD, a global dataset of more than 38,000 georeferenced dams. Scientific Data 7 (31).

Nardi, F., Annis, A., Di Baldassarre, G. et al. (2019). GFPLAIN250m, a global high-resolution dataset of Earth's floodplains. Sci Data 6, 180309. https://doi.org/10.1038/sdata.2018.309

Olarinoye, T., Gleeson, T., Marx, V. et al. (2020). Global karst springs hydrograph dataset for research and management of the world's fastest-flowing groundwater. Sci Data 7, 59. https://doi.org/10.1038/s41597-019-0346-5

Or, D. (2020). The tyranny of small scales - on representing soil processes in global land surface models. Water Resources Research, doi.org/10.1029/2019WR024846

Oreskes, N., Shrader-Frechette, K., \& Belitz, K. (1994). Verification, Validation, and Confirmation of Numerical Models in the Earth Sciences. Science, 263 (5147): 641646. 
Perrin, C., Michel, C. \& Andréassian, V. (2003). Improvement of a parsimonious model for streamflow simulation. Journal of Hydrology, 279(1-4), 275-289

Pfister, L. \& Kirchner, J.W. (2017). Debates - Hypothesis testing in hydrology: Theory and practice. Water Resources Research, 53, 1792-1798.

Popper, K. (1959). The logic of scientific discovery. 2002 Routledge Edition.

Price, K. (2011). Effects of watershed topography, soils, land use, and climate on baseflow hydrology in humid regions: A review. Progress in Physical Geography, 35(4), 465-492.

Rahman, A.S.M.M., Rosolem, R., Kollet, S.J. \& Wagener, T. (2019). Towards a computationally efficient free-surface groundwater flow boundary condition for largescale hydrological modelling. Advances in Water Resources, 123, 225-233.

Reichstein, M., Camps-Valls, G., Stevens, B., Jung, M., Denzler, J., Carvalhais, N., \& Prabhat (2019). Deep learning and process understanding for data-driven Earth system science. Nature, 566, 195-204.

Rogger, M., Pirkl, H., Viglione, A., Komma, J., Kohl, B., Kirnbauer, R., Merz, R. \& Blöschl, G. (2012). Step changes in the flood frequency curve: Process controls. Water Resources Research, 48, W05544, doi:10.1029/2011WR011187.

Ruddell, B.L. \& Kumar, P. (2009). Ecohydrologic process networks: 1. Identification. Water Resources Research 45 (3).

Sarrazin F, Hartmann A, Pianosi F, Rosolem R, Wagener T (2018). V2Karst v1.1: A parsimonious large-scale integrated vegetation-recharge model to simulate the impact of climate and land cover change in karst regions. Geoscientific Model Development, 11(12): 4933-4964 , doi:10.5194/gmd-11-4933-2018

Savenije, H.H.G. (2010). HESS Opinions "Topography driven conceptual modelling (FLEXTopo)". Hydrology and Earth System Sciences, 14, 2681-2692, doi.org/10.5194/hess14-2681-2010.

Seibert, J., \& McGlynn, B.L. (2007). A new triangular multiple flow-direction algorithm for computing upslope areas from gridded digital elevation models. Water Resources Research, 43, W04501, doi:10.1029/2006WR005128.

Shen, C. et al. (2018). HESS Opinions: Incubating deep-learning-powered hydrologic science advances as a community. Hydrology and Earth System Sciences, 22, 5639-5656. doi.org/10.5194/hess-22-5639-2018

Sivapalan, M. (2009). The secret to 'doing better hydrological science': change the question! Hydrological Processes, 23, 1391-1396. https://doi.org/10.1002/hyp.7242

Sivapalan, M., Blöschl, G., Zhang, L., \& Vertessy, R. (2003). Downward approach to hydrological prediction. Hydrological Processes, 17 (11), 2101-2111.

Stolbova, V., E. Surovyatkina,B. Bookhagen, \& J. Kurths (2016). Tipping elements of the Indian monsoon: Prediction of onset and withdrawal. Geophysical Research Letters,43, 3982-3990,doi:10.1002/2016GL068392.

Straatsma, M.W., Vermeulen, P., Kuijper, Marijn, Bonte, Matthijs, Niele, Frank \& Bierkens, M.F.P. (2016). Rapid screening of operational freshwater availability using global models. Water Resources Management, 30 (9), 3013-3026. 
Syvitski, JPM, CJ Vörösmarty, AJ Kettner, P Green (2005). Impact of humans on the flux of terrestrial sediment to the global coastal ocean. Science 308 (5720), 376-380

Taylor, RG, B Scanlon, P Döll, M Rodell, R Van Beek, Y Wada, et al. (2013). Ground water and climate change. Nature Climate Change, 3(4), 322.

Tetzlaff, D., McDonnell, J.J., Uhlenbrook, S., McGuire, K.J., Bogaart, P.W., Naef, F., Baird, A.J. Dunn, S.M., Soulsby, C, 2008. Conceptualizing catchment processes: simply too complex? Hydrological Processes, 22:1727-1730, DOI: 10.1002/hyp.7069.

Troy, T.J., Wood, E.F. \& Sheffield, J. (2008). An efficient calibration method for continentalscale land surface modeling. Water Resources Research, 44 (9).

Tshitoyan, V., Dagdelen, J., Weston, L., Dunn, A., Rong, Z., Kononova, O., Persson, K.A., Ceder, G. \& Jain, A. (2019). Unsupervised word embeddings capture latent knowledge from materials science literature. Nature, 571, 95-98.

Viegas, F.B., Wattenberg, M., van Ham, F., Kriss, J. \& McKeon, M. (2007). ManyEyes: a Site for Visualization at Internet Scale. IEEE Transactions on Visualization and Computer Graphics, 13(6), 1121-1128.

Vörösmarty, CJ , PB McIntyre, MO Gessner, D Dudgeon, A Prusevich, et al. (2010). Global threats to human water security and river biodiversity. Nature, 467 (7315), 555.

Wada, Y, LPH Van Beek, CM Van Kempen, JWTM Reckman, S Vasak, et al. (2010). Global depletion of groundwater resources. Geophysical Research Letters, 37(20).

Wang, G. (2019). Humans in the Loop: The Design of Interactive Al Systems. https://hai.stanford.edu/news/humans-loop-design-interactive-ai-systems. Accessed March 2020.

Wagener et al. (2007). Taking the pulse of hydrology education. Hydrological Processes, 21, 1789-1792.

Winsemius, H.C., Aerts, J.C.J.H., van Beek, L.P.H., Bierkens, M.F.P., Bouwman, A., Jongman, B., Kwadijk, J.C.J., Ligtvoet, W., Lucas, P.L., van Vuuren, D.P. \& Ward, P.J. (2016). Global drivers of future river flood risk. Nature Climate Change, 6 (4), 381-385.

Yan, D., Wang, K., Qin, T. et al. (2019). A data set of global river networks and corresponding water resources zones divisions. Sci Data 6, 219. https://doi.org/10.1038/s41597-0190243-y

Yang, Y. et al. (2019). In quest of calibration density and consistency in hydrologic modelling: Distributed parameter calibration against streamflow characteristics. Water Resources Research, doi.org/10.1029/2018WR024178.

Young, P. (2003). Top-down and data-based mechanistic modelling of rainfall-flow dynamics at the catchment scale. Hydrological Processes, https://doi.org/10.1002/hyp.1328.

Young, P., Parkinson, S. \& Lees, M. (1996). Simplicity out of complexity in environmental modelling: Occam's razor revisited. Journal of Applied Statistics, 23 (2-3), 165-210. 

(a)

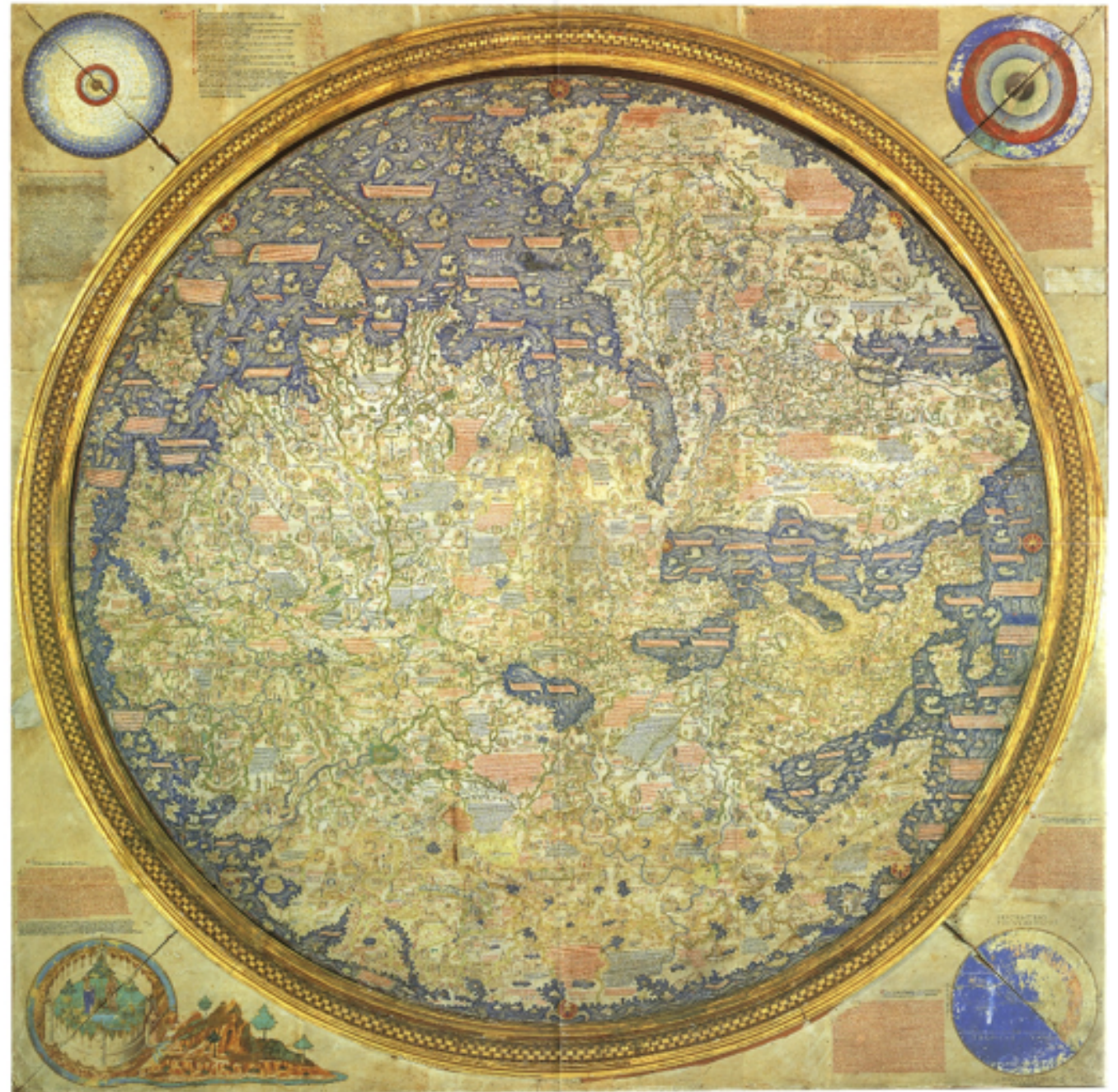

(b)

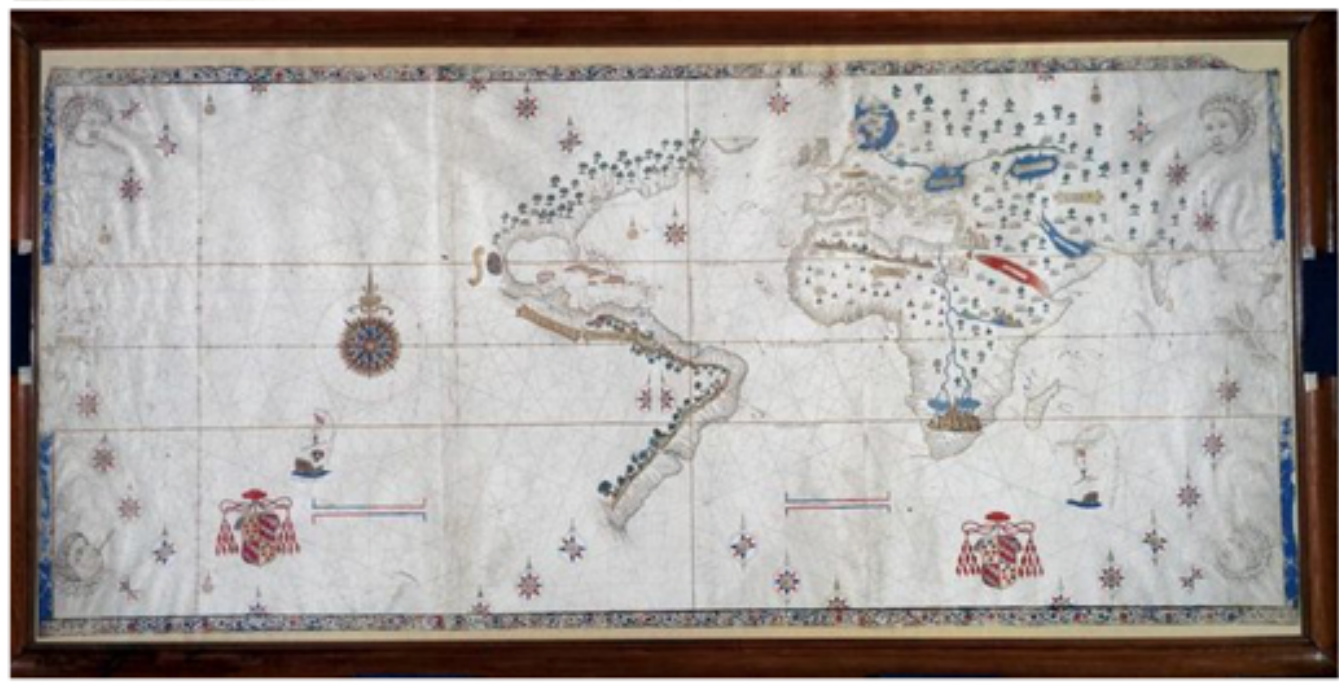

Figure 1. (a) The Fra Mauro world map from 1459 shows seemingly complete knowledge of the world. However, on closer inspection, maps like this one included statements like HIC SUNT LEONES and images of monsters in unexplored regions. (b) The Salviati Planisphere is a world map from 1525 without imagined representations, highlighting knowledge gaps. (Source, accessed March 2020: https://en.wikipedia.org/wiki/World_map) 

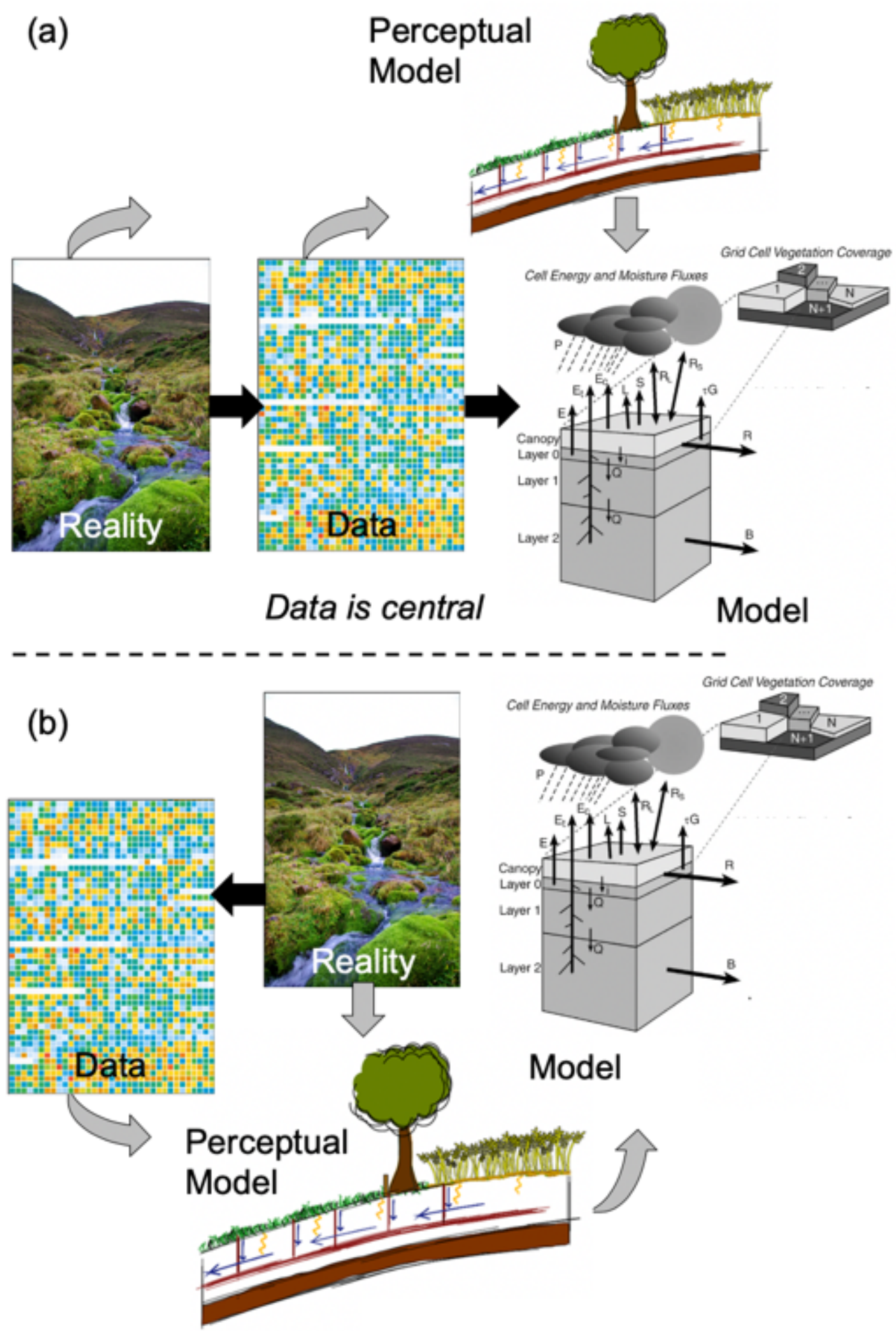

Perceptual model is central

Figure 2. Two versions of a workflow for hydrologic analysis. (a) The current modelling paradigm is strongly focused on data (observations) as being central to the modelling effort. (b) An alternative strategy is to place the perceptual model central. Black arrows stand for 'generates' and grey arrows stand for 'informs'. (Perceptual model picture taken from Loritz et al., 2017; Reality picture taken by Fabian Nippgen; Model image from Cherkauer et al., 2003). 
Advances in Water Resources

Number of Papers published per

Year in Key Hydrology Journals

Hydrological Sciences Journal

Hydrological Processes

Journal of Hydrology

Hydrology and Earth System Sci.

Water Resources Research

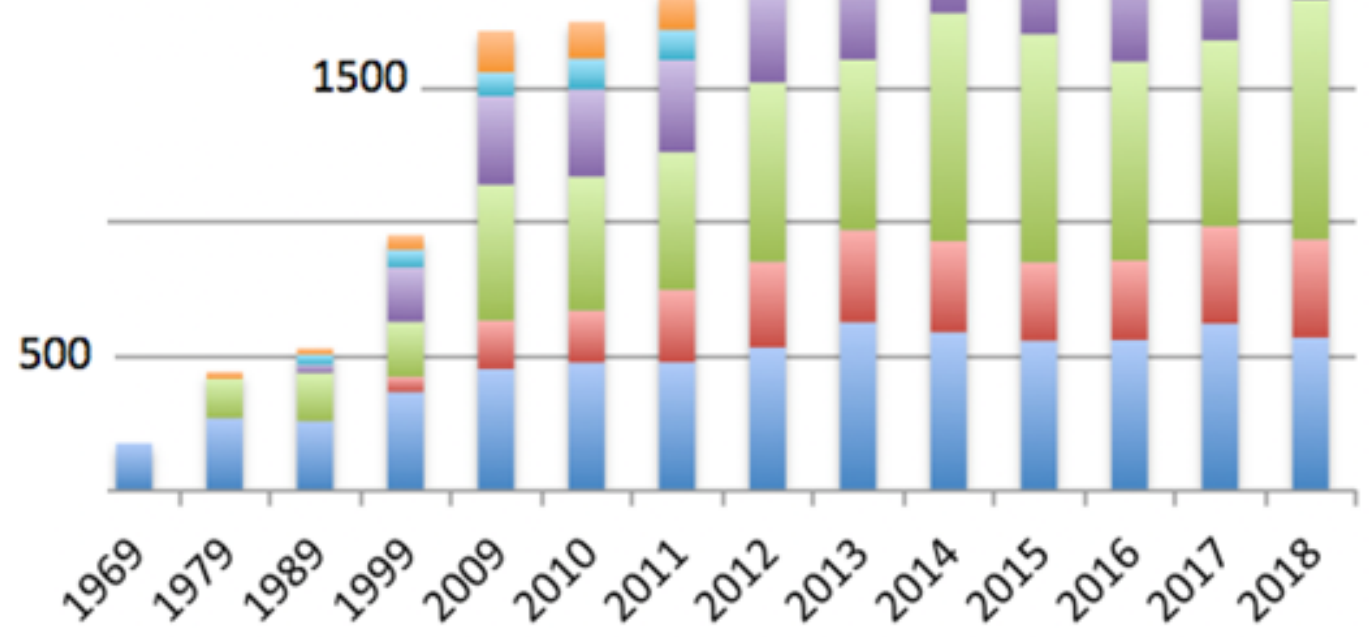

Figure 3. Number of papers published per year in key hydrology journals. Based on a Web of Science search in March 2020. 